\section{THE TOBACCO HABIT.}

Beisg the Norman Kerr Lecture delivered before the Society for the StUdY OF INEbRIETY,

BY

W. E. DIXON, M.D., F.R.S.

(Fren the Pharmacological Laboratory, Cambriclge.)

Nicotine, next to caffeine, is the alkaloid most widely used by man, and as in the last twenty years a truly enormous increase in the consumption of tobacco has occurred, it is right that a society like this, which concerns itself with every form of inebriety, should interest itself in the effects of smoking, both on the health of the individual and of the population as a whole. Disraeli" said "the youth of a nation are the trustees of posterity" ; and if the numbers of men rejected as unfit for military service in the late war form any criterion of the physical efficiency of our sons, few can doubt that British stamina leaves much to he desired, if it is not indeed on the wane. I believe that no excuse is necessary for calling attention to certain known facts concerning tobacco smoking. The late Dr. Norman Kerr, whose memorial lecture I have the honour to deliver to-day, wrote on some of the evils of tobacco, and especially its action in producing eve defects.

\section{Historical.}

Europe learned the use of tobacco from the American Indians. Tobaceo is an Indian word, but nicotine is named after the French Ambassador in Lisbon, Jean Nicot: he grew tobacco seed in his garden, and vaunted the leares as a cure for all external diseases. Snuff obtained from Nicot was introduced by Catherine de Medici at the French Court about $1560^{\circ}$ as a specific for headaches.

Tobacco was brought into this country by Ralph Lane in 1586; he taught its use to Ralegh, who became a devotee, did much to popularize it, and carried his habit even to the saffold. By the serenteenth century the use of tobacco had spread to almost erery European conntry.

A reaction against its use arose in the fifteenti and sixteenth centuries. James I published in 1603 a pamphlet entitled "Misocapnus seu de abusu Tabaci Lusus reginus," in which he says:

" $O$ cives, si quis pudor, rèm insanam abjicite, ortem ex ignominia, recepiam errore, frequentatem stultitia: unde et ira numinis accenditur, dignitas gentis senescit domi, vilescit foris; rem usu turpem, olfactu insuavem, cerebro noxiam, pulmonibus damnosam, et si dicere liceat atri fumi nebulis tartareos vapores proxime repraesentantem."

The Tsar Michael punished his soldiers with the rack and knout for smoking; Urban VIII forbade the use of tobacco in any form in church during divine service. How serious must have been the abuse of tobacco in Spain in 1642 may be gauged from the apostolic brief which tells us that the priests chewed tobacco during service, contaminated the vestments with expectoration, and filled the church with fumes. Benedict XIII, himself a snuff-taker, rescinded the prohibition in 1724 , but ordered that the use of tobacco in the Church of St. Peter at Rome should cause no disturbance; smoking was consequently excluded, though I believe that the use of snuff is allowed in Catholic churches to-day. Nevertheless, neither the King's book, the Czar's knout, nor the Pope's proclamation seriously affected the use of tobacco.

To the Puritans in England of the seventeenth century smoking was the mark of the drunken Cavalier. Nevertheless, the Roundheads later indulged, since Evelyn states that the soldiers took tobacco at Cromwell's funeral. The association of smoking with the roisterer and drunkard prevented its acceptance in society till the end of the eighteenth century. During the Regency the meerschaum and cigar appeared in the strects, but in no clubs except the military. Cigarettes reached us from Spain. A Greek, John Theodori, who settled in Leicester Square in 1861, was the first to make them in this country, and, being more portable and easily concealed, they quickly invaded the home. Nevertheless, it was not really till postVictorian days that the respectability of smoking was established. Women were the most bitter opponents of tobacco till this time; with their emancipation about a third of the women started to smoke, and now it is even unusual for either a maid or matron to abstain.

The use of tobacco, then, has become universal throughout the world. In this country no serious attempt has been made to determine its effect on the public health. America has been more active. Miss Lucy Gaston, under the auspices of the Anti-cigarette League, has been instrumental in organizing several national congresses. 'The twentieth amendment to the Constitution of the United States of America, which has never been ratified, provides that: (1) The manufacture, sale, transportation, inhalation or otherwise consumption of cigars, cigarettes, pipe tobacco, cut plug, and snuff is hereby prohibited. (2) The Congress and the several States shall have concurrent power to enforce this article by appropriate legislation, and to appoint enforcement officers in every community.

\section{Composition of Tobacco Smoke.}

The smoke emitted from any smouldering vegetable matter, including tobacco, contains ammonia gas and pyridine or pyridine derivatives, and it is these substances which produce the irritation of mucous surfaces not infrequently observed in those who smoke; these badies are responsible for the morning congh, the irritation of the throat and tongue, and the conjunctivitis of the cigarette smoker. They are in every respect objectionable products and add nothing to the pleasure of smoking. If they could be excluded from the smoke it would be all to the benefit of the smoker. Other dried herbs-such, for example, as coltsfoot leaves, at one time sold as a boys' tobacco which was harmless-often produce more pyridine when allowed to smoulder than tobacco, but they have none of its calming effects.

The pyridine bases are oily rolatile liquids, intensely irritant, but, compared with nicotine, of a relatively low toxicity. ${ }^{2}$ Their poisonous nature I have demonstrated on young rolunteers, who were required to smoke coltsfoot leaves; after smoking for some time (twenty to thirty minutes) they suffered from nausea, vomiting, and diarrhoea, with all the signs of early shock. ${ }^{3}$ Nevertheless in tobacco smoking the only serious effect of these bodies is the local irritation, since their specific effects are insignificant in comparison with those of other substances which are present in this smoke.

\section{Carbonic Oxide.}

Another substance obtained from the slow combustion of almost any regetable matter, including tobacco, is carbon monoxide, which is also the poison of coal-gas and the exhaust gas from motor cars.

In New York and Newhaven, where the motor traffic is dense, $\mathrm{CO}$ can be detected in the air of the streets. ${ }^{4}$ The traffic control men not infrequently suffer from headache, slight nausea, muscular weakness, and rapid pulse, which are the usual symptoms of $\mathrm{CO}$ poisoning. Wilson and others ${ }^{5}$ examined the blood of fourteen foot traffic patrol men and found that it contained from 0 to 30 per cent. of $\mathrm{CO}$, whilst six of these men showed values of from 20 to 30 per cent. Two other symptoms which are also prevalent are dizziness, and, more rarely, dimness of vision.

The United States Bureau of Mines made experiments to determine the $\mathrm{CO}$ present in a confined space after intensive smoking, and found that the $\mathrm{CO}$ concentration of the air of the room did not rise to more than 0.01 per cent., and the maximum blood saturation of the subjects exposed to this atmosphere was only 5 per cent. Nevertheless this is more than enough seriously to affect sensitive people. When the amount of this gas is determined in the smoke of cigars, cigarettes, and pipes under conditions simulating as far as possible those obtaining during ordinary smoking the figures obtained are somewhat alarming. ${ }^{6}$ The cigarette smoke rields from 0.5 to 1 per cent.; the pipe 1 per cent. or more, and the cigar 6 to 8 per cent.; this last, as 
Professor Armstrong points out, is roughly the proportion of CO in the coal-gas of the South Metropolitan Company. The amount of $\mathrm{CO}$ varies naturally with the rapidity of the smoking and the closeness of the packing-the quicker the smoking the more $\mathrm{CO}$.

Tobacco smoke, however, reaches the mouth freely diluted with air, and the amount of $\mathrm{CO}$ absorbed from the buccal cavity is negligible, so that pipe and cigar smokers who do not inhale have little to fear from this poison. Cigarette smokers who inhale would absorb a large proportion of the $\mathrm{CO}$ which reaches the lungs, since the affinity of $\mathrm{CO}$ for blood is more than two hundred times that of oxygen. Cigarette smoke as it reaches the mouth of the smoker may contain as much as 7.2 to 25 parts of $\mathrm{CO}$ in 10,000 parts of air (Baumberger). Inhaled for one hour at the rate of five puffs a minute this should be enough to affect appreciably the blood haemoglobin. Many years ago Fokker asserted that animals placed in an atmosphere containing tobacco smoke died from CO poisoning. Hartridge ${ }^{7}$ found 6 per cent. CO in the blood in one cigarette smoker who was by no means excessive in his habits. The normal healthy man does not in most cases show symptoms of $\mathrm{CO}$ poisoning until 15 to 20 per cent. of his haemoglobin has been fixed and put out of action. Yet there are many people who show a supersensitiveness to this poison, just as some of us have some idiosyncrasy for quinine or iodides, and so it is not difficult to appreciate why cigarette smokers may exhibit a syndrome indistinguishable from that of mild CO poisoning.

The toxic concentration of $\mathrm{CO}$ in the atmosphere is about 0.05 per cent.; in men exposed to dilute concentration, such as 0.02 per cent., the degree of haemoglobin saturationwould be perhaps somewhere near 20 per cent. ${ }^{7}$

\section{NrCotrins.}

The third and by far the most important constituent of tobacco is the volatile alkaloid nicotine. The effects of cigar and pipe smoking are due practically entirely to nicotine, which exists in tobacco combined with organic acids. During smoking these salts are largely dissociated, a part of the nicotine being burnt and a part passing in the smoke as free nicotine. The drier the tobacco the greater the destruction of the nicotine. Moist tobacco produces much more serious effects than dry tobacco, and it has been stated that the moistness of the tobacco is responsible for many of the evils. The water content of the tobacco is much more harmful to the smoker than the original nicotine content of the tobacco.

During the slow combustion of a cigar as in ordinary smoking there is an area immediately behind the point of combustion in which the water and other volatile substances condense. During aspiration the hot gases are drawn through this hot moist area and carry with them the volatile principles, of which nicotine is the most important. Hence the smaller this moist area behind the point of combustion-which means, the cooler the smoke or the more complete the combustion-the less likely is the smoke to contain volatile toxic bodies. It follows that a cigarette or slender cigar which is well cooled will yield fewer of these products than a thick cigar, and many smokers can testify that a fat cigar has a much greater effect than a long slender cigar of similar tobacco. This also explains the unpleasant effects of relighting a half-finished cigar or pipe.

The same principle is exemplified by the following fact. Virginian tobacco leaf from which cigarettes are made often contains double the amount of nicotine that is present in Manila cigars. Yet when an equal weight of the cigarettes and cigars is smoked the total cigar smoke contains double the amount of nicotine present in the cigarette smoke. The condition of the tobacco and the form in which it is smoked are more important factors in determining the amount of nicotine in the smoke than the amount of nicotine present in the original tobacco.

The species of plant mostly used is $N$. tabacum, but several other species are employed; thus $N$. rustica yields Turkish tobacco; different varieties of tobacco from the same species also show different amounts of nicotine. During the process of curing the leaves, which consists in exposing them under cover to a considerable degree of heat, important chemical changes occur, the leaves become moist and their fragrance alters. There is much room here for further investigations, with a view to producing a tobacco which when smoked would yield in the smoke the minimum of alkaloids, pyridine, etc., whilst retaining its aroma. Tobacco may contain anything from 1 to 8 per cent. of nicotine; Havana tobacco has about 1.5 per cent.; Maryland 2 per cent.; Virginia 6 per cent.; Kentucky 8 per cent.

\section{Amount of Nicotine in Smoke.}

The amount of nicotine in tobacco is no criterion of the amount in its smoke. For example, mild honeydew contains only 1.6 per cent., whilst Cavendish may contain as much as 3.8 per cent.; if these two are smoked under identical conditions the Cavendish naturally yields the larger amount of nicotine in the smoke. But Cavendish smoked in a cool pipe or one provided with a filter will affect the smoker less than the honeydew smoked in a hot pipe. In the churchwarden pipe the opportunity for the nicotine to condense is such that the smoke is almost freed from the alkaloid; and I have already pointed out that in cigar and cigarette smoking the degree of moisture, the tightness of packing, and the thickness of the cigar or cigarette are the most important factors in determining the amount of nicotine which will be present in the smoke. Habermann $^{8}$ and Ehrenfeld state that two-thirds of the nicotine of some kinds of cigars passes over in the smoke; with other brands as little as one twenty-fourth passes over. 1 Lehmann ${ }^{9}$ obtained nicotine from the air of a room in which tobacco was being consumed, showing that the smoke puffed out is by no means denuded of all its alkaloid. He thinks from his calculations that only about $1.4 \mathrm{mg}$. nicotine is absorbed from a cigar. This figure depends on so many conditions that it cannot be accepted-for example, the length of time that the smoke is held in the mouth, thus affording time for absorption, would exert an enormous influence. Our own observations suggest that the figure is ten times too small. The collapse which $I$ have seen in youths smoking a Manila cigar could not have been. produced by the absorption of such an amount.

Asherton (1919) says that 6 to $8 \mathrm{mg}$. of nicotine reach the mouth from a cigarette smoked in the usual way. We are not told, however, how much of this is likely to be absorbed. In our own observations, using a standard Virginian cigarette weighing 1 gram and aspirating the smoke through solvents once in twelve seconds, and using only three-fourths of the cigarette, it was found that $3 \mathrm{mg}$. of nicotine were absorbed. It must not be assumed that all this is necessarily absorbed into the system, but in the case of an inhaler most of it certainly is, perhaps 75 per cent., since expectoration is no longer permitted and loss can occur through the exhaled smoke only. Hence if a cigarette smoker were to puff ten cigarettes on end he would certainly absorb 20 to $30 \mathrm{mg}$. of nicotine-enough to produce a profound physiological effect, though, administered in this way, perhaps ten to fifteen times under the lethal dose. The amount of nicotine in pipe and cigar smoking is much higher. In our experiments cigar smoke contains about twice as much nicotine as cigarette smoke.

Other constituents of tobacco smoke are less important. The solids of cigarette smoke weigh about 10 per cent. of the tobacco burned-that is, $80 \mathrm{mg}$. for each cigarette. Cyanides and sulphocyanides are present in traces; arsenio is a constituent of American tobaccos in amounts many times greater than those permitted in foods. Pipe tobacco is reported to contain the equivalent of from 0.05 to 0.27 grains $\mathrm{As}_{3} \mathrm{O}_{3}$ per $\mathrm{lb}^{10}$ When smoked probably about half this will be absorbed.

These facts show that nicotine is a most important constituent of tobacco. It is one of the most fatal and rapid poisons known; it acts as quickly as prussic acid, and two drops placed on the tongue of a dog will kill it almost immediately. The lethal dose for a man is 60 to $120 \mathrm{mg}$. The nicoiine present in one cigar if injected intravenously would represent two fatal doses to man. It is therefore somewhat remarkable that fatal nicotine poisoning is not more common. Nevertheless the careless use of 
tobacco infusions in enemas, the occasional swallowing of tobacco leaves, or even carrying tobacco leaves next to the skin for smuggling purposes, have all led to fatal results. ${ }^{n}$ Tobacco has also been used for criminal purposes, ${ }^{12}$ but as it does not appear to undergo fermentative changes in the cadaver it can be detected in the bodies of animals three months after death.

\section{Denicotinized Tobacco.}

If tobacco is heated at a temperature over $100^{\circ}$ it gives off an empyreumatic oil which was official in the $U$. $S$. Pharmacopoeia of 1870 as oleum tabacci. This oil is rich in nicotine, has an odour resembling foul pipes, and is extremely toxic. Various methods have been adopted to eliminate the nicotine from the smoke and the juice which is apt to form in pipes. A porous substance may be put into the stem of the pipe; the space for cooling and condensation may be increased, or some substance which facilitates oxidation may be placed in the bowl of the pipe. These last pipes are called catalytic, and the bowls are lined with some metallic oxide, like that of platinum, in $a^{\text {. }}$ fine state of division. By passing tobacco smoke over the catalyser formol is formed and the nicotine and pyridine derivatives are decomposed. These pipes have not, howover, found favour.

Another method of improving tobacco consists in removing some of its nicotine by means of solvents. These so-called denicotinized tobaccos have 50 per cent. or more of their nicotine removed, and have been regarded therefore by physicians as relatively harmless, at all events as far as their nicotine is concerned. ${ }^{13}$ Unfortunately this is not the case, because it has been shown that these denicotinized cigars yield in their smoke as much nicotine as was present in the same class of cigar before denicotinization. ${ }^{14}$

Improved methods of removing the nicotine are, however, now being experimented with abroad. Boxes of cigarettes and tobaccos in various forms are treated with superheated steam; by this means practically the whole of the nicotine is said to be removed and the tobacco is left nicotine-free; the nicotine has a ready sale for agricultural purposes. I have had no opportunity, however, of experimenting with these products.

It will be obvious from this that great opportunities exist for investigating and improving tobaccos. Tobacco is a substance foreign to the body and its alkaloid is poisonous; the user pays heavily for his vice in taxes, and it is surely not unreasonable that he should have some further guarantee of the quality of the material which he buys than that provided by the 1842 Act. I am not suggesting that tobacco should be guaranteed to contain not more than a specified amount of nicotine, in the same way as spirits are standardized for alcohol; but as tobacco is similar to alcoholic beverages, in that excess of both leads to serious results, the public should have some sort of guidance or protection. It is almost certain, for example, that it is the moistness of the tobacco which is indirectly responsible for many of its most serious effects; that the pyridine derivatives are largely responsible for morning cough, which leads later to chronic bronchitis and cardiac failure. These are conditions which at least are capable of improvement. The Ministry of Health, which has already done much for providing pure foods of a certain standard, will, I hope, before long see in tobacco an important factor in the public health.

\section{Acrion of Tobacco Syoke.}

Tobacco used in any form possesses irritant properties; this is, of course, obvious with snuff, the use of which depends on stimulation of the fifth nerve endings. The same action occurs in chewing, which excites reflex salivation. If five or six grains of tobacco are swallowed vomiting occurs. Tobacco is irritating also to the skin, and the alkaloid in it is readily absorbed. Many cases of poisoning are on record, and $I$ have in mind particularly a child of 8 years, suffering from tinea capitis, to whoso head the expressed juice of tobacco leaves was applied; the treatment was shortly followed by death. Several cases of tobacco poisoning through the skin are reported in the British Medicat. Journal for 1926. Garvin in 1913 described the case of a girl aged 6 years who died forty-five minutes after receiving an enema of 24 grains of tobacco. From an examination of such cases it is clear that death may occur from three minutes to several hours after using tobacco as an enema or for application to the skin.

Continuous smoking for several years not infrequently produces signs of chronic irritation in the mouth, throat, and larynx-sore tongue, morning cough, hoarseness, tonsillitis, or chronic bronchitis. I believe that these effects are most marked in the cigarette inhaler. When the smoke is concentrated on one portion of the tongue for many years, which may occur especially in pipe smoking, this constant irritation is said to favour the formation of epithelioma of the lip and tongue if the quantity consumed is large or the smoker predisposed.51 The evidence in support of nicotine taking any part in this action is certainly not conclusive. Nevertheless, Bottini mentions one hundred cases of cancer which he saw, including three women, which were caused by smoking or chewing tobacco. On the other hand, the Registrar-General's report show's a remarkable fact to which attention has not been drawn previously-that tobacco manufacturers have a lower death rate from cancer than those of any other trade.

Smoking is reputed amongst the public to have an antiseptic action, and is sometimes indulged in nominally for this purpose. Pepys describes the use of tobacco during the plague, and its use was compulsory at Eton in 1721 as a prophylactic against " the apprehension." Puntoni ${ }^{15}$ and others have shown that tobacco smoke has a strong disinfectant action in vitro. When the smoke is drawn into the mouth, however, the action is attenuated by the saliva and mucosa, and its antiseptic effect is negligible. The action in vitro is not influenced by filtering the smoke free from nicotine by passing it through cotton-wool.

\section{Spfeific Action.}

Smoking is, however, indulged in by man because of its sedative action, and this is due solely to nicotine absorption. Nicotine stimulates all nerve cells throughout the body without exerting any kind of selective action, and the stimulation is followed by depression. The time the stimulation lasts depends on various factors, but as a rule it coincides with the absorption of the nicotine-that is, with the period of active smoking. Both the pleasures and evils of smoking are intimately connected with nicotine. Morphine, heroin, cocaine, and other drugs of addiction have a selective action on the central nervous system alone; nicotine is different, it acts also on the autonomic nervous system, and it is this action which produces objectionable effects in the sensitive or excessive smoker.

\section{Alimentary Canal.}

The commonest symptoms of smoking are loss of appetite and chronic intestinal catarrh. The smoker's lack of appetite, Sir Humphry Rolleston thinks, is not altogether an evil, since it limits the consumption of unnecessary food. Nicotine; and tobacco smoking, by stimulating the autonomic ganglia, increase the secretion of the alimentary glands, and later, after the smoking has ceased, depress them; hence the salivation during smoking and the dry mouth the following day. The same fact is true of gastric secretion. Experiments have been made on dogs with a Heidenhain's fistula, by means of which the secretion of gastric juice may be collected and examined as desired. Injections into these animals of nicotine or saline solution through which smoke has been passed afford a means of determining accurately the effect on gastric secretion. Both affect the dog in the same way, and cause at first a decided increase in gastric secretion. ${ }^{16}$ It is well recoga ded that in certain persons excessive smoking leads to this gastric hypersecretion; hyperacidity is the most common disturbance, and gastritis acida is one of the most frequent results. Hurst ${ }^{17}$ believes that tobacco smoking' is one of the most frequent causes of hyperchlorhydria. Rolleston ${ }^{18}$ lays considerable stress on the relative sensitiveness of the individual as an important factor in determining whether or not a heavy smoker will pay the penalty of gastric disease:

On the musculature of the alimentary canal the action 
of tobacco is equally well marked, the automatic movements are first inhibited and later augmented, as a result of stimulation and later depression of the autonomic nervous system. ${ }^{19}$ The inhibitory stage is almost coincident with the period of smoking, and is associated with contraction of the pyloric and ileo-colic valves. Stimulation of the sympathetic nerves causes inhibition of the whole alimentary canal with the exception of these two valves, which are cortracted. The dyspepsia often following on a hypodermic injection of morphine is probably due to this pyloric contraction, which delays the passage of food. Morphine in this respect shows some similarity to nicotine. The mild laxative action of tobacco smoke may be explained by the ultimate depression of the inhibitory cells whereby the motor nerves assume an undue influence on the automatic movements.

Hunger is due to certain well recognized automatic contractions of the stomach; smoking definitely inhibits these. Hence continuous smoking staves off the pangs of hunger, and acts in this respect like the drugs of addiction - cocaine and morphine. Careful experiments which have been made on habitual smokers and non-smokers with the aid of bismuth and $x$ rays show that the effect of smoking a cigar is to stop the normal automatic movements of the stomach within fifteen minutes. The inhibition continues until about three minutes after smoking has ceased, when the contractions begin again. ${ }^{20}$ In these experiments it was also shown that nausea and vomiting from excessive absorption of nicotine may occur at a time when the stomach movements are completely inhibited.

Tobacco smoking, then, has a very definite action on the alimentary canal. In certain sensitive people it produces effects which, according to Hurst, favour the production of duodenal ulcer, whilst Wagner ${ }^{21}$ insists that excessive smoking can produce all the subjective and $x$-ray appearances of this condition.

\section{Circulation.}

The considerable use of tobacco in any form invariably produces certain definite effects on the circulation which cause no inconvenience of any kind to the subject; these should be distinguished from other effects which only occasionally occur, but are then often sufficiently distressing to induce the sufferer to seek medical advice.

Under the first group must be included changes in the pulse rate. All observers are agreed that the use of tobacco increases the pulse rate from five to ten beats a minute, and in the case of the man who is continually smoking the increase of rate becomes permanent, but this condition produces no apparent disadvantage.

When the novice or moderate smoker puffs a cigar the rate of the pulse increases in a few minutes. Lee, ${ }^{22}$ working in my laboratory, demonstrated this clearly both in the novice and moderate smoker under strict experimental conditions. In another series of experiments twenty-eight young healthy smokers were required to smoke a single Turkish cigarette; the pulse rate increased in all but four and sixteen showed an increase of more than eight beats a minute. ${ }^{23}$ Hesse $^{24}$ obtained similar results with cigars on twenty-five patients suffering from various chronic diseases.

During the war it was generally asserted that excessive smoking, particularly of cigarettes, was the common cause of the so-called D.A.H. Observations were made which showed that the average pulse rate of the patients during smoking was nine beats a minute higher than before smoking; in ten healthy controls it was six higher. ${ }^{25}$ As there can be no question that the effect is due to nicotine, inhalers of cigarette smoke should show more acceleration than non-inhalers. In Parkinson's twenty patients the ten inhalers showed an average increase of pulse rate of eleven a minute and the ten non-inhalers of seven.

This increase in the pulse rate is associated with a small rise in blood pressure; for the moderate smoker the rise does not usually exceed $20 \mathrm{~mm}$. of $\mathrm{Hg}$ systolic, and $8 \mathrm{~mm}$. of $\mathrm{Hg}$ diastolic, and is usually even less. The rise begins a few minutes after the smoking has commenced and is maintained throughout the smoking period. ${ }^{24} 26 \mathrm{It}$ is only $i_{11}$ the case of the novice or after excessive smoking that the blood pressure falls to any extent below normal after the smoking has ceased; but under certain conditions the fall may be so severe as to cause all the signs and symptoms of shock or collapse. ${ }^{22}$

Observations have also been made to determine the effect of smoking continued over a period of six months. Nicolai and Staehelin smoked six or eight cigars a day for six months. They then gave up smoking, except for an occasional cigar, for a further six months. Their average pulse rate was 74.5 , compared with 81.8 during the smoking period. ${ }^{27}$

These changes from the normal are, after all, usually small and give rise to no symptoms, but the evidence available suggests that they cannot be regarded with indifference. It is a maxim with those who are in training for athletic events that smoking must be entirely eschewed. This prohibition, no doubt adopted in the first place as the result of experience, has become a tradition. In Nicolai's experiments the acceleration of the pulse which occurred after the performance of a measured amount of work with the ergograph was considerably greater during the smoking period, while recovery to the normal rate was much slower than during the period of abstinence. Parkinson and Koefod also showed that smoking a few cigarettes can render healthy men more breathless on exertion, and that this effect was marked in soldiers suffering from D.A.H. This means that the heart even of the moderate smoker is less efficient in periods of strain. It is possible, then, that the prohibition of smoking for athletes is dependent on this vascular effect. With present knowledge it would be mere speculation to attempt to gauge the significance of this factor when continued over many years.

\section{More Serious Circulatory Effects.}

of the more definite effects which cause patients to seek advice are palpitation and arrhythmia, which are relatively common in the young; they disappear if the smoking is stopped, though in pronounced cases, as the late $\mathrm{Sir}$ Clifford Allbutt pointed out, only after the abstinence has been continued for many months. The arrhythmia is functional and is usually due to extra-auricular systoles. Neuhof mentions fibrillation and flutter and sino-auricular block also; the block in the case he illustrated disappeared three days after smoking ceased, ${ }^{28}$ but such cases must be very rare. Rolleston says that arrhythmia may occur at any age but is more noticeable after 50 ; this may be due to a loss of tolerance which is known to occur in later life.

Another symptom which may arise from excessive smoking in later life is anginoid pain, which, according to Osler, rarely approximates to true angina. Turney says that it is associated with vasomotor disturbances and tends to occur after meals or in the night rather than after exertion.

Arterio-sclerosis is easily produced in animals, especially rabbits, by the injection of nicotine, and we have ourselves produced marked arterial changes in the aorta and larger produce of animals by administering to them "smoke water "; but I do not think that these experiments aro proofs that smoking leads to arterio-sclerosis in man, although there is a consensus of clinical opinion that immoderate smoking favours arterio-sclerosis. Pawinski ${ }^{29}$ states that 42 per cent. of 1,000 cases of coronary sclerosis had histories of immoderate smoking.

In severe cases the cardiac irregularities may lead to syncope, and an undue proportion of sudden deaths during the middle period of life, without any definite lesion found post mortem, is said to occur in heavy smokers. ${ }^{13}$ As even the most moderate smoking places some disability on the heart, trifling though it be, it may well be that this view deserves serious consideration.

\section{Central Nervous System.}

Nicotine is essentially a nerve poison, but so far consideration has only been given to its action on the cells on the course of the autonomic system, and this action is responsible for the digestive and circulatory effects. But nicotine affects the brain and cord also: it increases spinal reflexes and removes certain inhibitions.

I have already drawn attention to some of the effects 
of excessive cigarette smoking in the young, the attacks of giddiness, and the tremors. A large experience of examination papers of medical students enables me to pick out with certainty the heavy cigarette smokers, from the irregular character of their writing. If the habit is broken the writing at once improves and the vertigo disappears. These effects are exactly those of $\mathrm{CO}$ poisoning, and $I$ believe can be explained on this basis.

Habitual smokers are agreed that the weed acts as a mild sedative to the central nervous system; the type of action is of a somewhat remarkable character and may offer an explanation of the widespread use of tobacco. Physical fitness or well-being is determined by our feelings, which are the result of sensations. If response to sensation varies from the normal, whether on the hypo or hyper side, rest causes a return towards the normal, and smoking is said to exert a similar effect, though of a more marked description; hence the sedative effect of tobacco in conditions of irritation, and the stimulating effect in those of weariness and depression. The experiments from which these statements were deduced consisted in determining the threshold to single break induction shocks of two fingers immersed in saline solution. After this figure was determined the subject smoked two cigarettes and his threshold was re-examined. If the initial threshold was low, smoking depressed it on an average 72 per cent. On the other hand, if the initial threshold was high, smoking loxvered it on an average 28 per cent. Suitable controls tre made with cubebs cigarettes, which always acted as a stimulant. This shows also that the tobacco action is due to nicotine. ${ }^{30}$ In the same way smoking tends to nullify the slight sensory depression produced by the veronals, antipyrinc, and other hypnotics. ${ }^{31}$ So that it may well be that tobacco is helpful when the sensory threshold is abnormal.

\section{Mental Efficiency.}

Mental efficiency tests on the whole have not been very convincing. In Berry's experiments ${ }^{32}$ smoking enabled his subjects to do more rapid and correct arithmetical addition; but the nicotine here was not the determining factor, the aroma, and holding an unlighted cigar, or chewing substances like gum all had some effect. Turney lays much stress on the importance of these tics. Carver's experiments consisted in applying eight established psychological tests in a number of people to determine whether cigars or cigarettes would influence their judgement and response t.) stimuii. The results suggest that smoking lowers the accuracy of finely co-ordinated reactions and associationthought processes. The speed of complicated reactions was, however, unchanged. The habitual smoker, when deprived of his smoke for some hours, showed diminished accuracy. ${ }^{33}$

Many observations have been made by merely comparing the efficiency, mental or physical, of smokers and non-smokers. All these experiments seem to me so difficult to interpret that their value is negligible. Generally they show some inferiority of the smokers. This is true of observations of scholarship, ${ }^{34}$ endurance of telegraph workers, ${ }^{35}$ scholarship and physical efficiency, ${ }^{36}$ and resistance to tuberculosis. ${ }^{37}$ The apparent inferiority may be the cause or the effect of the tobacco habit. Those who are handicapped by neurosis or other form of inferiority would succumb nost easily to the euphoria of smoking.

The action of smoking on the performance of routine muscular work has also been examined, and it has been found that habitual smoking has no obvious effect on the output of work amongst glass-blowers, a moderately strenuous physical occupation, although chewing greatly diminished the output. ${ }^{38}$ On the other hand, Lombard's experiments show that smoking diminishes muscular endurance both at the age of 35 and $60 . .^{39}$ Using the ergograph, Palman found that cigarette smoking at first increased muscular work, but that fatigue set in earlier and the total work was less. A curious periodicity occurs in the ergograph records after smoking, due to fatigue or depression of the central nervous system. ${ }^{40}$

It must be conceded that ordinary smoking in normal people does not lead to nervous disturbances. Excessive smoking is another matter, and may produce anxiousness and insomnia. Every smoker knows that a stronger cigar than usual may keep him awake, though usually the effects of smoking are soothing and favour sleep. Neurasthenic subjects are easily affected by smoking; they are continually breaking off their smoking and returning to it again in a few weeks. They suffer from headaches, dizziness, and sudden sharp attacks of pain in the head, over the precordial region, or in the stomach, which cease when the smoking is stopped. ${ }^{41}$ Neuralgias, generally stated to be localized about the intercostals, humoral and scapular region, are rare, but of importance, as the pain continues until the cause is removed.

The action of tobacco, then, on the central nervous system, when used in moderation, on the whole does no harm, and in subjects showing deviations from the normal it makes for good.

\section{Amblyopia.}

Tobacco amblyopia stands alone in mischiefs so grave. It was noticed by Mackenzie in 1835 and observed accurately by Hutchinson in 1864 . The sight gradually becomes dim with central scotoma, some derangement of accommodation, and often dilatation of the pupil. This condition is associated with retrobulbar optic neuritis, and recovers if smoking is stopped; when degeneration has set in, however, abstaining from nicotine will only arrest further progress. ${ }^{41}$

At one time those engaged in the manufacture of tobacco, in consequence of the absorption of powder, suffered from visual troubles. Dr. Norman Kerr stated: "In 3,000 workers in a tobacco factory 150 had eye defects, 45 being seriously affected." Galezowski, de Schweinitz, and many others have verified these facts. Nevertheless with improved sanitary arrangements these effects have now disappeared.

Androgué, in a critical analysis of 48 cases of amblyopia from axial neuritis due to nicotine, says the quality of the tobacco is at fault; it was imperfectly dried, which means that the percentage of nicotine in the smoke is mitch greater than usual.42

\section{Tolerance.}

The rapidity with which people become accustomed to nicotine is well known, but is none the less remarkable. The degree of tolerance varies in different people, but it is never absolute. Wahl in 1920 found that non-smokers suffered from nausea and vomiting after taking by the mouth 1 to $2 \mathrm{mg}$. of nicotine. On the other hand, smokers required more than $8 \mathrm{mg}$. to produce the same effect.

Various methods are known by which tolerance to drugs may be attained. Habitual dosing with a drug is sometimes met by diminished absorption, or the drug may combine with some substance which renders it non-toxic. Salicylic acid is rendered inactive by combining with glycocoll, though whether it is possible to attain a tolerance by this means is not known. Tolerance can also be attained by destruction of the toxic agent; here alcohol affords an example, for whilst it is true that all mammals can oxidize this body, the rate of oxidation may be increased by habit. This method of obtaining tolerance by destruction applies to alkaloids also, as was shown by Faust ${ }^{43}$ for morphine, and Cloetta ${ }^{44}$ for atrophine.

Many investigators claim that tolerance to nicotine cannot be produced in animals, but the methods employed were not of the kind which would show small degrees of tolerance. All the experiments, however, show that whatever the condition of the animal as regards tolerance, if nicotine can reach the tissue upon which it acts-that is, nerve cells--it produces its normal effect. This leaves only two probable explanations of the tolerance in man. The first is that nicotine is not absorbed in the tolerant man. Clinical evidence rebuts this supposition; it is well recognized that excessive smoking may produce toxic effects -alimentary, cardiac, and nervous-even in the most inveterate smokers. The second explanation is that the nicotine is destroyed as an active substance, but that the rate of destruction is limited. ${ }^{45}$ If the destruction were carried out only slowly by the tissues, like the oxidation of alcohol and sugar, that would not necessarily prevent the nicotine exerting. a physiological action; and if the rate of absorption exceeded that of destruction, a nicotine 
action would certainly, be obtained. When nicotine is introduced directly into the circulation the destruction within a few seconds would be negligible, and so the whole of the specific action would be obtained, no matter what the degree of tolerance.

The experiments of Lee and myself ${ }^{46}$ were made on rabbits, and showed that repeated injections of nicotine into an animal give to the tissues, and especially the liver, an increased power of destroying the toxicity of the nicotine. It is easy to conceive of several ways in which this might be brought about, but some of these possibilities may be eliminated by experiment.

The loss of activity proceeds very slowly; this might be anticipated, for if it occurred rapidly a high degree of tolerance would be expected, and this never occurs. It does not then, a priori, seem likely that the cause of the loss of activity can be explained on the supposition of a chemical combination. The evidence rather points to some form of destruction of the nicotine, the process being possibly of the nature of a ferment action.

Although strong evidence exists in support of the view that tolerance means increased rate of destruction, yet there is some evidence suggesting that the nicotine is taken up specifically by certain tissues; Heger and others have shown that when nicotine is injected into the circulation of animals it disappears quickly from the blood and is taken up by the liver, from which it can be obtained by distillation.

Edmunds ${ }^{47} 48$ made similar experiments to ours on dogs. $\mathrm{He}$ showed that the livers of all dogs possess some power of destroying nicotine, and suggested that the destroying agent is probably a ferment. Further, he says that it is possible that this ferment may be increased in quantity by the constant use of the alkaloid, but his experiments on dogs failed to prove it. The success or failure of these experiments depends, however, entirely on having adequate controls, and these are more difficult to obtain with dogs than rabbits. Fühner ${ }^{49}$ thinks it is entirely unnecessary to assume tolerance at all. He points out that nicotine is excreted in the urine and that it is not cumulative; he neglects the clinical evidence.

Several clinicians have recorded cases showing a gradual drop in tolerance with advancing years. Turney and Rolleston both lay some stress on this. Finkelnburg says that patients, when once they have experienced symptoms of poisoning by nicotine, the particular form of which is immaterial, become more susceptible to the action, so that a smaller quantity of tobacco will reproduce the toxic symptoms. In this respect nicotine poisoning differs from most if not all chronic toxaemias produced by drugs. Rolleston also draws attention to the fact that diseasefor example, influenza-may destroy an acquired tolerance.

Tolerance can exist also against CO. Animals such as guinea-pigs will live for months in an atmosphere in which as much as one-quarter of their blood haemoglobin is put out of action by combination with $\mathrm{CO}$. They acquire a tolerance which is due to an increase in the corpuscles and hacmoglobin, so that the oxygen capacity of the blood becomes almost normal. If such an animal is placed in a normal atmosphere it slowly loses its $\mathrm{CO}$, its available haemoglobin increases, and it appears to suffer some discomfort. It is possible that the craving of the cigarette smoker after a period of abstinence may be not unconnected with this.

\section{WHY WE Syoke.}

I suppose few things are more difficult to analyse than the complex which gives rise to content, satisfaction, or positive pleasure. Any incident which breaks some simple habit acquired by long usage causes not only inconvenience but positive annoyance. The ritual of the pipe and cigarette soon becomes a most pronounced habit. The short duration of the cigaretto leads to the frequent repetition of a series of complicated acts, culminating in the lighting up. The ritual of pipe smoking is even more likely to lead to a tic. To finger or suck an unlit pipe, to fill it, or to be repeatedly lighting it becomes in time a series of complicated reflexes which all go to make up the tic. I am informed that tobacco put up in cartons containing suffcient to fill the pipe, thus depriving the habitue of the ritual of filling, is not popular among smokers.
The element of rhythm plays its part: it is well recognized that with certain people some form of rhythmical movement facilitates thought and gives satisfaction. Dancing, singing, and chewing gum give satisfaction partly through their rhythm, and rhythm enters largely into smoking.

Sight and smell are other important factors. Sir Robert Armstiong-Jones ${ }^{50}$ says that the cloud of white smoke rising before the smoker is soothing and companionable, and it is well knowh that people who become blind generally, but not quite invariably, give up smoking, and that smoking in the dark does not give the same satisfaction as smoking in the light. The fragrant smell and taste of good tobacco are also stimulating; so that taste, smell, and sight all take their part in the content. The amount of nicotine in the smoke is certainly not the determining factor in the pleasure; were this so we should employ moist cigars and so the more quickly satiate our desires; aroma is more important.

Pleasure, then, depends upon at least these factors:? (a) reflex stimulation from the mucous membrane of the mouth and nose; (b) the tic complex; (c) the drug action, due mainly to nicotine, and perhaps to a smaller degree to the $\mathrm{CO}$ in the case of the cigarette smoker. The principal action of tobacco depends on the narcotic effect of the nicotine; it produces repose and calm-what I should term a stabilizing action. The cigar and pipe smoker, during a period of abstinence, feels the want of this customary effect.

The habit of smoking is sometimes referred to as an addiction. Rolleston ${ }^{51}$ discusses this question, and all it is necessary to say here is that addiction is a relative term; the most powerful drug of addiction is probably heroin, and then follow cocaine, morphine, Indian hemp, opium, alcohol, and last tobacco.

A drug addict wishes to be freed from the cares and worries incidental to existence. To do this a drug must either depress the higher faculties of mind-judgement, self-control, inhibitions of all kinds-leaving free play for tho lower and emotional centres; or the more primitive and emotional centres of the brain must be excited. Nicotine would most certainly be a drug of addiction were its action confined to the central nervous system, but it also acts on the autonomic system, so that when smoking is pushed-that is, when larger amounts of nicotine are absorbed-nausea, vomiting, diarrhoea, faintness, prostration, and collapse follow. The true addict is held in bondage by the fear of withdrawal and the craving which follows it. With tobacco this does not exist; the loss of one's smoke is an annoyance, but hardly a tragedy, and few. cannot, when necessity arises, entirely abstain.

On Certain Economical Factors.

During the last fifteen years an enormous increase has taken place in the consumption of tobacco. In America the number of cigarettes consumed in 1914 was 3,000 million; in 1918, after the war, this had increased to 46,000 million; but the figure continues to increase, and in 1921 it reached 52,000 million. The per capita consumption of tobacco in the United States of America in 1920 was $6.3 \mathrm{lb}$; in Great Britain it was $3.17 \mathrm{lb}$. Increased consumption appears to obtain in all European countivies. In Holland smoking is especially prevalent. In 1924, 2,500 million cigarettes were consumed at a cost of $3 \frac{1}{2}$ million pounds; some statistics ${ }^{52}$ show that of 100 boys aged 6 years, 30 smoked; of boys between 9 and 10, 50 smoked; and of 250 boys more than 11, 220 smoked.

In Austria a pamphlet was published in 1924 by sereral of the most distinguished Vienna doctors to their confreres which states that: "Nicotine promotes arterio-scletrosis and nervous diseases. In our country the cost of tobacco for one day equals the total annual deficit of all our tuberculosis sanatoria which it was necessary to close for. economy." In Germany the total expenditure for the German army in 1912 was less than its smoking bill. As a further example of the cost of tobacco to a nation, Professor Farnum of Yale University has estimated that the United States of America in 1921 spent well over 300 million pounds on tobacco.

The Governments of the world are slowly appreciating 
that the tobacco habit is not an unmixed blessing. England has passed legislation prohibiting the sale of tobacco to all minors under 16. Japan has a law prohibiting smoking by all persons under 20. The Austrian and German Republics are showing active interest against the further expansion of the tobacco habit, and most of the States in America have some form of legislation aimed at limiting the tobacco habit.

\section{Conclusion.}

Tobacco smoking serves as a mild stimulant followed by a slight degree of narcosis, the supersensitive become calm and lose their irritability, and the dull and apathetic are stimulated. The physiological evidence clearly points to this effect, but the explanation has yet to be learned. Smoking, however, leads to digestive and circulatory disturbances. There is an increasing impression amongst clinicians that the insidious action of nicotine spread over many years of continuous absorption is responsible for at least some of the cardio-rascular diseases so common in middle and later life.

It may be argued that if nicotine adds to the agreeableness of life, why not use a path so pieasant? In persons of vivid sensations, to calm the commotion of conflicting sensations may be beneficial, even to the higher faculties; in the dull and listless to stimulate thought must be beneficial. It may well be that living in a civilization such as ours, under the conditions of strain imposed by residence in cities, the ordinary man shows in his nervous responses variations from the normal, and on such tobacco exerts a beneficial function. To what extent strict moderation in the use of tobacco leads to vascular degeneration is uneertain; is it the rule or the exception? This is the vital question to which we require an answer, and upon this answer something of the well-being of the nation depends.

In conclusion I venture to suggest that the collective sagacity of this society, and that of the medical profession as a whole, could occupy itself with no subject more important to the nation than that of tobacco smoking.

1. Disraeli, in Sybil.

REFERENCES.

2. Tiedemann: Geschichte des Tabaks, 1854, p. 137

McKendrick and Dewar : Ber. d. d, Chem. Ges. 1874, p. 1458. Harnack and Meyer : Schmied. Arch. 12, 394, 1880. Brunton and Tunnicliffe :

Jourin. Physiol., 17, 272, 1894.

4. Henderson and Haggard: Journ. Amer. Metl. Assoc., 81, 385, 1923.

5. Wilson and others: Ibid., 87, 319,1926

6. Armstrong: BRTTSSH MEDTCAL JOCRNAL, 1922, i, 992.

7. Hartridge: Proc. Phys. Soc. January 31st, $1920.127,1922$

8. Habermann and Ehrenfeld : Zeit. Pep. Plingiol. Chem 1922.

9. I.ehmann: Münch. med. Woch., 55, 723, 1908; A Ach. f. Hyg., 68, 319, 1909.

10. Remington: Journ. Anier. Chem. Soc.. June, 1927.

II. ז. Hildenbrand: Jouru. d. prakkt. Heilli., 13, 151, 1801. Namias: Gaz. des Hôp. p. 461,1864 .
New York Med. Journ.

12. New York Med. Journ., N.S. 9.

13. Turney : Med. Mag., October, 1913, p. 14.
14. Van Leeuwen : Schmied. Arch., 84, 283, 1918.

15. Puntoni : Annali d'Igiene, $30,469,1920$.

16. Skaller: Berl. kilin. Woch., Decenber 6th, 1909.

17. Hurst : Medical. Eszays and Addrezses, London, 1924

18. Rolleston: Practitioner, January, 1927, p. 1

20. Carlson and Lewis: Amer. Journ. Physiol. 34, 149, 1914

21. Daniélopolu and others: C. R. Soc. de Bit.

22 Lee: Quart. Journ. Exper. Physiol., i, $335,1908$.

23. Aikman : New York Hed. Journ., 102, 891, 1915.

84. Hesse: Deut. Arch. f. l.lin. Med., 89, 555, 1907.

25. Parkinson and Koefod: Lancet, August 18th, 1917. Bruce Miller and Hooker : Amer. Journ. Physinl., 24, 104, 1909. Frankl.
Hochwart: Deut. Zeit. A Nervenheilkunde, 47-48, 128, 1913. John: Zeit. exp. Path., 14, 332, 1913 .

27. Nicolai and Staehelin: Zeit. exp. Path., 8, 323, 1910.

Neuhof: Arch. Int. Merl., 17, 659, 1916.

30. Mawinski : Zeit. klin. Med., 80, 284, 1914. 2 , 549, 1925; Journ. Platm. and Exper. Theraj., 17, 333, 1921.

31. Hale and Grabfieid Journ. Pharm. and Exper. Therap., 21, 77, 1923.

32. Berry: P8ych. Bulletin, Princetown, 14, 25, 1917.

34. Carver : Journ. Comp. Psych., 2, 279, 1922.

34. Clark : Clark Coll: Reprints, U.S.A., 91, 1900:

35. Baumberger: Journ. Tharm. The Student who Smokes, Antioch Press, 1926.
37. Flick: Thobacco, Henry Phipps Inst., 1908.

\$8. Baumberger, Perry, and Martin: Journ. Ind. Hyg., 3, i, 1921.

39. tombard: Amer. Journ. Physiol., 40, 32, 1916.

40. Raphael Ibid., 52, 132, 1920

41. Keller: Med. Ǩlin., Berlin., 18, 1149, 1922

41A. Des A Ablyopias et Amauroses Toxiques, 1897, p. 47.

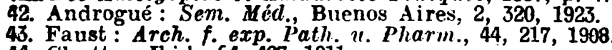

44. Cloetta : Ibid., 64, 427, 1911 .

45. Dixon: Proc. Roy. Soc. Med., 5, 1, 1911.

46. Dixon and Lee : Quart. Journ. Exper. Physiol., 5, 373, 1912

47. Edmunds: Journ. Pharm. and Exp. Therap., I, i, 1909.

48. Edmunds and Smith: Journ. Lab. and Clin. Med., i, 3.

49. Fühner: Schmied. Areh., 98, 370, 1923.

. Mrmstrong-Jones: Practilioner January, 1927, p. 16.

52. Rolleston: Lancet, May 22nd, Sociaal Weekblad, June, 1926.
X RAYS IN THE DIAGNOSIS OF INTRA'THORACIC GROWTHS."

BY

STANLEY MELVILLE, M.D.Brux., M.R.C.S., L.R.C.P., Barrister-at-Law,

Radiologist, St. George's Hospital, and Hospital for Diseases of the Chest, Brompton.

(With Special Plate.)

Is the pre-radiological days there were but few publications and very few discussions on intrathoracic neoplasms. Such references as there were dealt with the matter only from the standpoint of morbid anatomy. Out of 174 cases reported in 1904 by Sehrt, in six only had a correct clinical diagnosis been made. It is certainly less than a hundred years since neoplastic diseases of the chest were first subjected to any systematic examination, and less than thirty years since any such examination was possible in vivo by means of $x$ rays. In 1810 Bayle, a favourite physician of Napoleon, in his Recherches sur la Phthise Pulmonaire, coined the term " phthise cancéreuse," showing that even at that time morbid anatomy was not unaware of the relationship between the two diseases. The symptom-complex of increased intrathoracic pressure was pointed out by Bell of Glasgow and by Stokes of Dublin, but this was as far as our forebears would go in the way of clinical diagnosis. Nor is this attitude to be wondered at; in the first place, intrathoracic new growths were regarded as being of extremely rare occurrence, and, in the second place, the hopelessness of the prognosis was not conducive to any great enthusiasm.

It is customary to divide intrathoracic new growths into two classes: (a) benign, and (b) malignant. But it is only in the pathological sense that this distinction can be drawn, for every intrathoracic new growth, however benign in its pathology, will in time deprive the patient of life by a process of pressure. It seems well to appreciate this point, if for no other reason than that clinician and radiologist may be alive to the vital necessity for early diagnosis. Unfortunately, even true malignant neoplasms, as a rule, give so little evidence of their presence until they have grown to such a size as to cause pressure symptoms, or increasing breathlessness. Am I wrong in suggesting that on the very first evidence of even occasional breathlessness that cannot be accounted for the aid of the radiologist should be asked?. It is said that the day is approaching when every clinician will be so alive to the interpretation of a skiagraph that the radiologist will no longer be asked to carry out his proper function. I shall not live to see that day, but $I$ am sufficiently optimistic to feel that it will be many a long day before such a complete revolution takes place, and that the wiser the clinician, the more will he demand all the expert assistance possible in arriving at a diagnosis.

Bexigr Neoplasms.

These are for the most part extrapulmonary.

\section{Filnoma.}

The $x$-ray evidence is that of a well defined, more or less rounded opacity, which can be shown to arise from the posterior wall of the thorax, pushing in front of itself the lung and not directly invading it. Owing to the nonirritant nature of the structure of the fibromata, there is seldom any pleural adhesion, the lung surrounding the growth but able to be separated readily. Any further growth of the tumour tends to depress the diaphragm, push the heart and mediastinum to the opposite side, and to cause compression of the adjacent lung tissue.

Diagnosis is rendered easy by the simple expedient of collapsing the lung by the production of artificial pneumothorax, when the evidence of an isolated and free tumour, which is extrapulmonary, can be made out. This expedient of compressing the lung by the admission of air into the pleural cavity has not been utilized as much as it

* The opening paper in a discussion on this subject in the Section of Radiology at the Annual 